\title{
Social Network Analysis
}

\author{
Susha Jain ${ }^{1}$, Mahaveer Jain ${ }^{2}$, Balasubramani $\mathbf{R}^{3}$, Vasudeva Pai ${ }^{4}$ \\ Department of Information Science and Engineering, NMAM Institute of Technology, Nitte
}

\begin{abstract}
Social Network Analysis is an action of making inquiries about social network, which is also termed as social structures through the application of networks and Graph theory. To manage the social networks, different methodologies have been proposed to break down them. What has not been done is to appropriately and productively imitate, govern and utilize the social network. In this paper we are analyzing the twitter revolution data set. It is a social network which is a combination of many separate networks which captured a certain kind of interaction between individuals. We are applying island method and centrality concept on the data set. Here we can observe how the information diffusion happens among the individuals and also the actor and communities who plays the major role in process can be noticed.
\end{abstract}

Keywords: Twitter, Facebook, Google+ and LinkedIn, Organizational Network Analysis [ONA]

\section{INTRODUCTION}

With the approach of social networks, individuals are living in the period of data blast. Individuals are utilizing SNA for illuminating breaking news just as communicating one's sentiments and feelings. Be that as it may, it is drawing in more fascination as a device for correspondence in day by day life. Analysts have appeared expanded enthusiasm for concentrate social practices, human correspondence, and content mining by utilizing SNSs, for example, Twitter, Facebook, Google+ and LinkedIn.

To comprehend systems and their members, we assess the area and gathering of performing characters in the system. The measures give us the understanding into the different jobs and groupings in a system who are connectors, experts, etc. where are the clusters and who is in them, who is in the core of network and who is on the periphery? Social network Analyst measure the network movement for a node by utilizing the idea of degrees, the amount of direct associations the node has Social network hypothesis views social Connections as nodes and ties. Nodes are the individual performing characters inside the system of social network. Examining and displaying informal communities as mind boggling systems requires all the more understanding to the idea of mankind. On the off chance that we fabricated our comprehension to interpersonal organizations dependent on associated hubs and relations just, at that point we may finish up having no system from a human viewpoint. Two variables should be watched very cautiously; individuals are the wellsprings of data individuals have normal needs to get the data or to be its source. The term social network alludes to the verbalization of a social relationship, credited or accomplished, among people, families, families, networks. Every one of them can assume double jobs, acting both as unit or hub of social network just as social on screen actor. Connection is a typical case of a credited relationship, while some basic instances of an accomplished relationship are those that are built up over the span of standard association in the procedures of day by day life and living, social exercises, etc, for example, one family asking help, backing, or exhortation from another; ties of kinship or selection of people to get to know one another; and inclinations in marriage.

Unexpectedly, a relationship can likewise be negative-for example, antagonistic vibe or struggle as contradicted to kinship or union and estrangement versus commonality or incorporation. Once more, a lot of what we will talk about depends on sociological information, however it can likewise be utilized to contemplate statistic and monetary procedures, for example, relocation starting with one locale then onto the next, estimation of a financial (e.g., postal cash request or exchange) trade between locales, volume of stream of merchandise between nations, stream of traffic between better places, etc. In this way, the units of an "Social networks" can be unique, no uncertainty, for example, people, families, families, and provincial or urban zones, as indicated by the relationship under thought. In any case, there is a typical component - to be specific, whatever the sort of units we examine, a particular dyadic relationship exists or does not exist between the individuals from any pair of them.

The nodes in the system are the general population and gatherings while the connections show connections or streams between the nodes. SNA gives both a visual and a scientific investigation of human connections. The executives advisors utilize this strategy with their business customers and call it Organizational Network Analysis [ONA]. ONA enables you to x-beam your association and uncover the administrative sensory system that interfaces everything. In this paper we used twitter revolution data set to analyze and discover the individuals and communities who play a major 
role in the network. Also we can observe how the information diffusion happens from a common man to a celebrity that we ca observe how the particles of information move around the informal network. We use Island method and Centrality concept to analyze the social network.

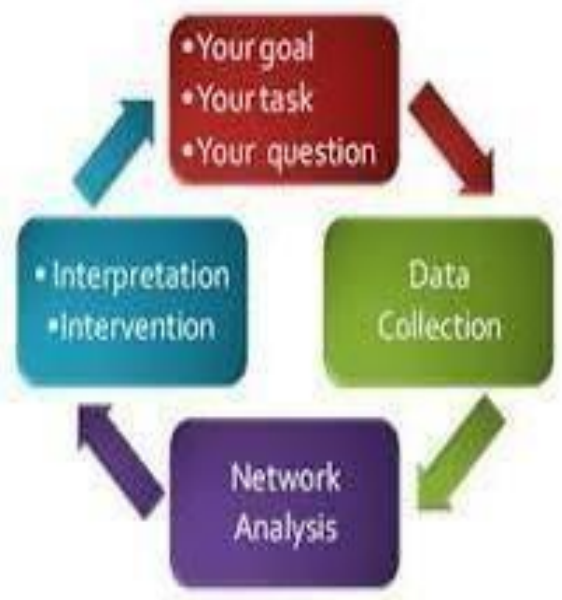

Fig. 1 Social Analysis Cycle

How utilizing a retweet organize for explicit clients, we can dispense key players and shrouded personalities who are conceivably having a similar belief system or possibly have a place with a similar gathering of intrigue, proposed measures to shape a completely weighted coordinated diagram where connections and hubs have determined qualities, and connections are just appointed at the presence of correspondence exchanges; the new measures can be utilized to anticipate impacts and data diffusions.

\section{METHODOLOGY}

We collected the retweets done during the period of twitter revolution. While its obvious that every news worthy event spreads in high spike in twitter dataset. Retweets represent the information that has been received, internalized and passed on others.Main purpose is to find the communities and influencers over the network. Network consists of 134973 number of retweets.

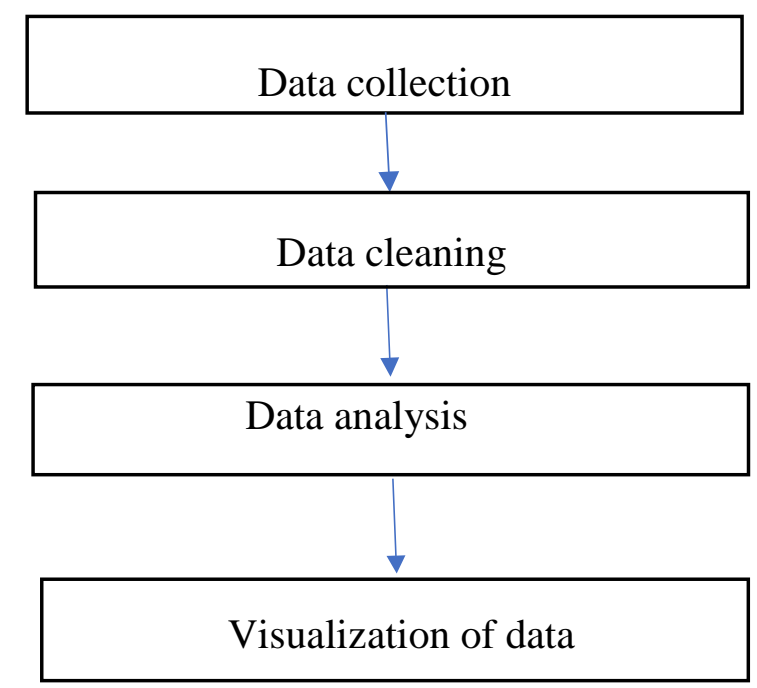

Fig. 2 Block Diagram

We apply Island method and Centrality concept in order to analyse the social Network. Utilization of Island method helps to break large network comprising of actors and individuals into small components, so that analysis of the network will be much easier. Through Centrality concept we can find the influencers over the network along the period of revolution. Also we can find how the information diffusion happens among the individuals and also the movement of information particles can be found.

[1] Software's and Packages Installed: [1]Anaconda 
Vol. 8, Issue 5, May 2019

Anaconda constrictor is a free and open source appropriation of the Python and $\mathrm{R}$ programming dialects for information science and machine learning related applications (expansive scale information preparing, prescient investigation, logical figuring), that intends to rearrange bundle the executives and organization.

[2] IPython

IPython (Interactive Python) is a direction shell for intuitive processing in different programming languages, initially created for the Python programming language, that offers reflection, rich media, shell punctuation, tab finish, and history.

[3] Matplotlib

Matplotlib is a plotting library for the Python programming language and its numerical arithmetic augmentation NumPy. It gives an article arranged API to implanting plots into applications utilizing universally useful GUI toolboxs.

[4] Flask

Flask is a small scale web structure written in Python. It is named a smaller scale structure since it doesn't require specific instruments or libraries. It has no database reflection layer, structure approval, or whatever other segments where prior outsider libraries give basic capacities

[5] Jupyter

Project Jupyter is a philanthropic association made to "create open-source programming, open- benchmarks, and administrations for intelligent processing crosswise over many programming dialects."

[6] NetworkX

NetworkX is a Python library for examining diagrams and systems. NetworkX is free programming discharged under the BSD-new permit.

\section{RESULTS}

Using Island Method and Centrality, Analysis is done on the network to find the communities and influencers. As a result we can find how the information diffusion happened during the course of time. Results obtained may represent the following figure:

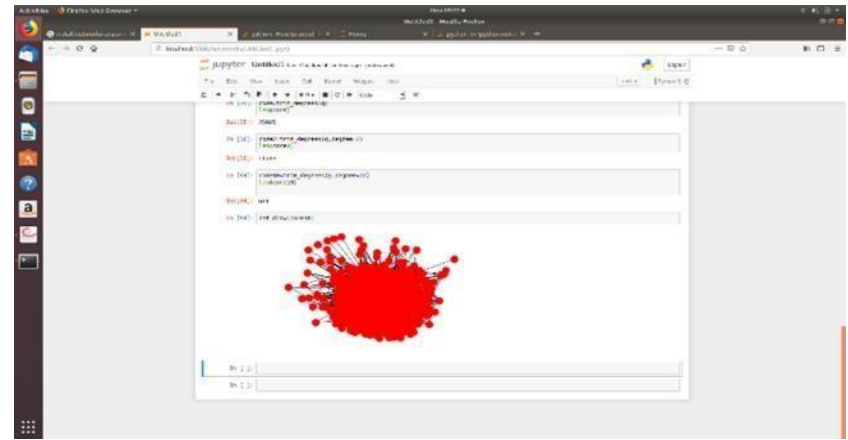

Fig. 3 Result obtained from Island Method

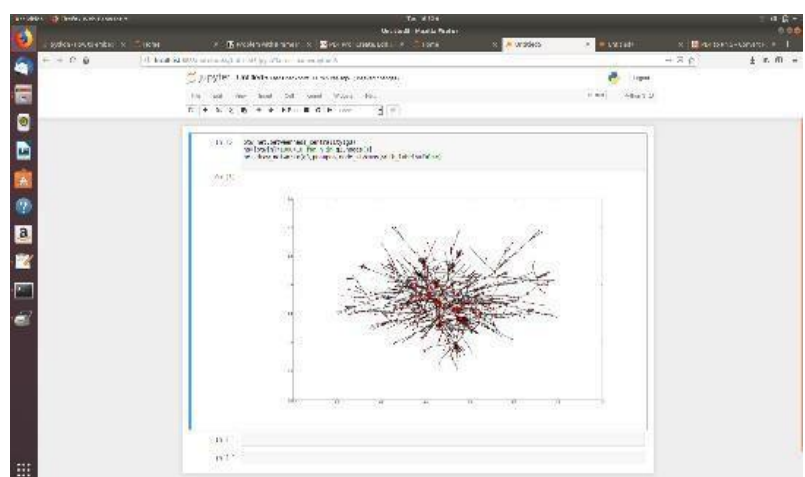

Fig. 3 Result obtained from between ness centrality

In Island method gaint network is divided into small components and each component is analysed separately. 
Betweeness centrality is measured by counting the number of times the node can appear in the shortest path between all the nodes in the overall network. Examining and displaying informal communities as mind boggling systems requires all the more understanding to the idea of mankind. On the off chance that we fabricated our comprehension to interpersonal organizations dependent on associated hubs and relations just, at that point we may finish up having no system from a human viewpoint. Two variables should be watched very cautiously; individuals are the wellsprings of data individuals have normal needs to get the data or to be its source.

In this way, the units of an "Social networks" can be unique, no uncertainty, for example, people, families, families, and provincial or urban zones, as indicated by the relationship under thought. In any case, there is a typical component- to be specific, whatever the sort of units we examine, a particular dyadic relationship exists or does not exist between the individuals from any pair of them. The nodes in the system are the general population and gatherings while the connections show connections or streams between the nodes. SNA gives both a visual and a scientific investigation of human connections. The executives advisors utilize this strategy with their business customers and call it Social Network Analysis [SNA].SNA enables you to x-beam your association and uncover the administrative sensory system that interfaces everything.

\section{CONCLUSION}

Networks are inevitable in all parts of life: natural, physical, and social. They are vital to the functions of a worldwide economy. Social network comes in various forms and structures. Analysing social network can empower a superior understanding of the number of ways people make families and compose on the network. In the proposed work we can observe how the information diffusion among the people. Likewise the networks and influencers dynamic over the span of time will be known

\section{REFERENCES}

[1]. Tuja Khaund, Kiran Kumar Bandeli, Muhammad Nihal Hussain1, Adewale Obadimu1, Samer Al-khateeb, Nitin Agarwal1 University of Arkansas at Little Rock Little Rock, USA, Creighton University Omaha, Nebraska, USA," Analyzing Social and Communication Network Structures of Social Bots and Humans".

[2]. Kaveh Ketabchi Khonsari ,Zahra Amin Nayeri, Ali Fathalian, Leila Fathalian Bachelor of Science, Department of Computer Science University of Tehran, North Kargar Ave. Tehran, Iran "Social Network Analysis of Iran's Green Movement Opposition Groups using Twitter".

[3]. Kajal Nusratullah Yanbu University College Yanbu Alsinaiyah, Saudia Arabia, Prof. Dr.Asadullah Shah KICT: International Islamic University Malaysia Gombak,Malaysia ,Prof. Dr. Shoab Ahmad Khan CE\&ME, National University of Sciences and Technology (NUST) Rawalpindi,Pakistan, Wasi Haider Butt CE\&ME, National University of Sciences and Technology (NUST) Rawalpindi,Pakistan "Detecting Changes in Context using Time Series Analysis of Social Network"

[4]. Wasserman, Stanley; Faust, Katherine (1994). "Social Network Analysis in the Social and Behavioral Sciences". Social Network Analysis: Methods and Applications. Cambridge University Press. pp. 1-27.ISBN 9780521387071.

[5]. SurajBandypadhyay; AR.Rao; BikasK Sinah(2011)." Models for social networks with statistical applications". Sage publication. ISBN 9781412941686.

[6]. Jennifer Xu, Byron Marshall, Siddharth Kaza Hsinchun Chen. Analyzing and Visualizing Criminal Network Dynamics: A Case Study. Lecture Notes in Computer Science[M]. Springer Berlin /Heidelberg, 2004 359-377.

[7]. MATTHEW J. DOMBROSKI , KATHLEEN M. CARLEY. NETEST: Estimating a Terrorist Network's Structure. Computational \& Mathematical Organization Theory, 8, 235-241, 2002.

[8]. Mansoureh Takaffoli, Farzad Sangi, Justin Fagnan, Osmar R. Zä1ane. Community EvolutionMining in Dynamic Social Networks, Department of Computing Science, University of Alberta,Edmonton, Alberta, Canada T6G 2E8: Procedia - Social and Behavioral Sciences 22 ( 2011) $49-58$.

[9]. Master's Thesis, Philipp Singer, Time Series Analysis of Online Social Network Data and Content: Knowledge Management Institute,Graz University of Technology September 2011.

[10]. Le T. Nguyen, Pang Wu, William Chan, Wei Peng, Ying Zhang. Predicting Collective Sentiment Dynamics from Time-series Social Media.

[11]. Ian McCulloh.Detecting Changes in a Dynamic Social Network March 31, 2009 CMU- ISR-09-104 Institutes for Software Research School of Computer Science Carnegie Mellon University Pittsburgh, PA 15213 Thesis Committee Kathleen M. Carley, Chair Carolyn Rose Cosma Shalizi (Statistics) Kevin Huggins (U.S. Military Academy).

[12]. Zhaobo Luo , Xiaohong Jiang, Yi Feng† and Chaolun Xia,Dynamic Core Detection in Social Network Analysis,343-347, 2009 Sixth International Conference on Fuzzy Systems and Knowledge Discovery.

[13]. NIU Dongxiao,SHI Hui, LI Jianqing, WEI Yanan, Research on Shortterm Power Load Time Series Forecasting model Based on BP Neural Network, 509-512, 978-1-4244-5848-6/10/2010 IEEE.

[14]. James A. Danowski,Noah Cepela Automatic Mapping of Social Networks of Actors From Text Corpora: Time Series Analysis, 137142,978-07695-3689-7/09 2009 IEEE.

[15]. James A. Danowski ,Semantic Network Analysis of Islamist Sources using Time Slices as Nodes and Semantic Similarity as Link Strengths: Some Implications for Propaganda Analysis about Jihad, 164-171,9780-7695-4782-4/12 2012 IEEE.

[16]. Marc A. Smith , Ben Shneiderman , Natasa Milic-Fraylin , Eduarda Mendes Rodrigues, Vladimir Barash , Cody Dunne , Tony Capone , Adam Perer, Eric Gleave, Analyzing (Social Media) Networks with NodeXL Telligent Systems.

[17]. N.Rosenthal, M.Fingrutd, M.Ethier, R.Karant, D.McDonald, "Social Movements and Network Analysis: A Case Study of Nineteenth-Century Women's Reform in New York State", The American Journal of Sociology, Vol. 90, No. 5, pp. 1022-1054, March 1989

[18]. Saunders \& Clare (2007). 'The national and the local: Relationships among environmental movement organisations in London'.Environmental Politics 16(5):742-764.

[19]. D.A Snow, L.A Zurcher Jr., S.Ekland-Olson, "Social Networks and Social Movements: A Microstructural Approach to Differential Recruitment", American Sociological Review, Vol. 45, No. 5, pp. 787801, Octobor 1980 
[20]. M.Garrido, A.Halavais, "Mapping Networks of Support for the Zapatista Movement". In M. McCaughey \& M. D. Ayers (Eds.), (pp. 165-184). New York: Routledge, 2003

[21]. V. Krebs, "Mapping networks of terrorist cells," 2002.[Online]. Available: http://citeseerx.ist.psu.edu/viewdoc/summary?doi= 10.1.1.16.2612

[22]. R.Steve, "Social Network Analysis as an Approach to Combat Terrorism: Past, Present, and Future Research." Homeland Security Affairs II, no. 2, July 2006

[23]. V. Mitliaga, "Networks and netwars - the future of terror, crime, and militancy," International Journal of Law and Information Technology, pp. 238-239, 2002. [Online]. Available: http://www.ingentaconnect.com/content/oup/inttec/ 2002/00000010/0000 0002/art00238

[24]. Bastian, Jacomy, Heymann, "Gephi : An Open Source Software for Exploring and Manipulating Networks", ICWSM'09, 2009.

[25]. Y. Hu, "Efficient, High-QualityForce-Directed Graph Drawing", The mathematica journal, V.10, Issue 1, 2006.

[26]. O. Gayer, "What is an Internet Bot | How Bots Can Hurt Your Business,” Incapsula Blog, 02-Feb- 2016.

[27]. @DFRLab, “Le Pen’s (Small) Online Army,” DFRLab, 06-Mar-2017.

[28]. E. Ferrara, O. Varol, C. Davis, F. Menczer, and A. Flammini, "The rise of social bots," Commun. ACM, vol. 59, no. 7, pp. 96-104, 2016.

[29]. E. Ferrara, "Disinformation \& social bot operations in the run up to the 2017 French presidential election," First Mon, vol.22, no.8, Jul. 2017.

[30]. N. Agarwal, S. Al-khateeb, R. Galeano, and R. Goolsby, "Examining the use of botnets and their evolution in propaganda dissemination," J. Def. Strateg. Commun., vol. 2, no. 2, pp. 87-112,2017.

[31]. J. Ratkiewicz, M. Conover, M. R. Meiss, B. Gonc,alves, A. Flammini, and F. Menczer, "Detecting and Tracking Political Abuse in Social Media," in Proceedings of the FifthInternational AAAI Conference on Weblogs and Social Media, 2011, pp. 297-304

[32]. S. Al-khateeb and N. Agarwal, "Examining botnet behaviors for propaganda dissemination: A case study of isil's beheading videos-based propaganda," in Data Mining Workshop (ICDMW), 2015 IEEE International Conference on, 2015, pp. 51-57.

[33]. O. Varol, E. Ferrara, C. A. Davis, F. Menczer, and A. Flammini, "Online Human-Bot Interactions: Detection, Estimation, and Characterization," ArXiv170303107 Cs, Mar. 2017.

[34]. C. A. Davis, O. Varol, E. Ferrara, A.Flammini, and F. Menczer, "BotOrNot: A System to Evaluate Social Bots," ArXiv160200975 Cs, pp. 273274, 2016.

[35]. S. Mittal \& P. Kumaraguru, "Broker Bots: Analyzing automated activity during High Impact Events on Twitter," ArXiv14064286 Phys, Jun. 2014.

[36]. N. Abokhodair, D. Yoo, and D. W. McDonald, "Dissecting a social botnet: Growth, content and influence in Twitter," in Proceedings of the 18th ACM Conference on Computer Supported Cooperative Work \& Social Computing, 2015, pp. 839-851.

[37]. M. Hawksey, "TAGS v6.0ns," Google Docs. [Online].Available:https://docs.google.com/spreads heets/d/1EqFm184RiXsAA0TQkOyWQDsr4e Z0XRuSFryIDun_AA4/edit?pli=1\&usp=embed_fa cebook\&usp=embed_faceb ook. [Accessed: 20- Mar-2018].

[38]. "Paterva Home." [Online]. Available: https://www.paterva.com/web7/. [Accessed: 26- Apr-2018]. [14] V. D. Blondel, J.-L. Guillaume, R. Lambiotte, and E. Lefebvre, "Fast unfolding of communities in large networks," J. Stat. Mech. Theory Exp., vol. 2008, no. 10, p. P10008,2008.

[39]. Berger, J. (2011). Arousal Increases Social Transmission of Information Psychological Science Journal.

[40]. Chen, P. Y. and Chen, K. C. (2010). Information Epidemics in Complex Networks with Opportunistic Links and Dynamic Topology. IEEE Global Telecommunications Conference (GLOBECOM 2010). Miami, Florida, USA.

[41]. Domingos, P. (2005). Mining Social Networks for Viral Marketing. IEEE Intelligent Systems, 20 (1).

[42]. Chen, P. Y. and Chen, K. C. (2010). Information Epidemics in Complex Networks with Opportunistic Links and Dynamic Topology. IEEE Global Telecommunications Conference (GLOBECOM 2010). Miami, Florida, USA.

[43]. Domingos, P. (2005). Mining Social Networks for Viral Marketing. IEEE Intelligent Systems, 20 (1). 